\title{
Intensification of Doxorubicin-Related Oxidative Stress in the Heart by Hypothyroidism Is Not Related to the Expression of Cytochrome P450 NADPH-Reductase and Inducible Nitric Oxide Synthase, As Well As Activity of Xanthine Oxidase
}

\author{
Jaroslaw Dudka, ${ }^{1}$ Franciszek Burdan, ${ }^{2}$ Agnieszka Korga, ${ }^{1}$ Magdalena Iwan, ${ }^{1}$ \\ Barbara Madej-Czerwonka, ${ }^{2}$ Monika Cendrowska-Pinkosz, ${ }^{2}$ \\ Agnieszka Korobowicz-Markiewicz, ${ }^{3}$ Barbara Jodlowska-Jedrych, ${ }^{4}$ \\ and Wlodzimierz Matysiak ${ }^{4}$ \\ ${ }^{1}$ Medical Biology Unit, Medical University of Lublin, 20-059 Lublin, Poland \\ ${ }^{2}$ Department of Human Anatomy, Medical University of Lublin, 20-059 Lublin, Poland \\ ${ }^{3}$ Department of Pulmonary Diseases and Pediatric Rheumatology, Medical University of Lublin, 20-059 Lublin, Poland \\ ${ }^{4}$ Department of Histology and Embryology, Medical University of Lublin, 20-059 Lublin, Poland \\ Correspondence should be addressed to Jaroslaw Dudka, ave123@wp.pl
}

Received 21 May 2012; Accepted 5 July 2012

Academic Editor: Ana Fortuno

Copyright ( 92012 Jaroslaw Dudka et al. This is an open access article distributed under the Creative Commons Attribution License, which permits unrestricted use, distribution, and reproduction in any medium, provided the original work is properly cited.

Cytochrome P450 NADPH-reductase (P450R), inducible synthase (iNOS) and xanthine oxidase play an important role in the antracycline-related cardiotoxicity. The expression of P450R and iNOS is regulated by triiodothyronine. The aim of this study was to evaluate the effect of methimazole-induced hypothyreosis on oxidative stress secondary to doxorubicin administration. 48 hours after methimazole giving cessation, rats were exposed to doxorubicin (2.0, 5.0 and $15 \mathrm{mg} / \mathrm{kg})$. Blood and heart were collected 4 , 48 and $96 \mathrm{~h}$ after the drug administration. Animals exposed exclusively to doxorubicin or untreated ones were also assessed. The hypothyreosis $(0.025 \%$ of methimazole) significantly increased the doxorubicin effect on the cardiac carbonyl group and they may increase the glutathione level. An insignificant effect of methimazole was noticed in case of the cardiac lipid peroxidation product, the amount of DNA oxidative damages, iNOS and xanthine oxidase-enzymes responsible for red-ox activation of doxorubicin. However, the concentration of P450R was affected by a lower dose of methimazole in rats administered with doxorubicin. Since in rats receiving doxorubicin changes in oxidative stress caused by methimazole were not accompanied by elevation of bioreductive enzymes, it may be concluded that these changes in the oxidative stress were not related to the tested enzymes.

\section{Introduction}

Doxorubicin is widely used as a chemotherapeutic agent, but its usefulness is limited by cardiotoxicity [1]. Cardiotoxicity is manifested as incurable congestive heart failure that may appear months or years after completion of chemotherapy [2]. Free radicals synthesised during the doxorubicin redox cycling are considered to be the starting point responsible for biochemical, morphological, and clinical symptoms [3-8].

Doxorubicin is enzymatically reduced with one electron which is transmitted to $\mathrm{O}_{2}$ (Figure 1). This cycle may by repeated many times, resulting in overproduction of superoxide anion radical $\left(\mathrm{O}_{2}{ }^{-*}\right) \cdot \mathrm{O}_{2}{ }^{-*}$ implies in synthesis of more toxic oxygen $\left(\mathrm{H}_{2} \mathrm{O}_{2}, \mathrm{HO}^{*}\right)$ and nitrogen $\left(\mathrm{ONOO}^{-}\right)$ 


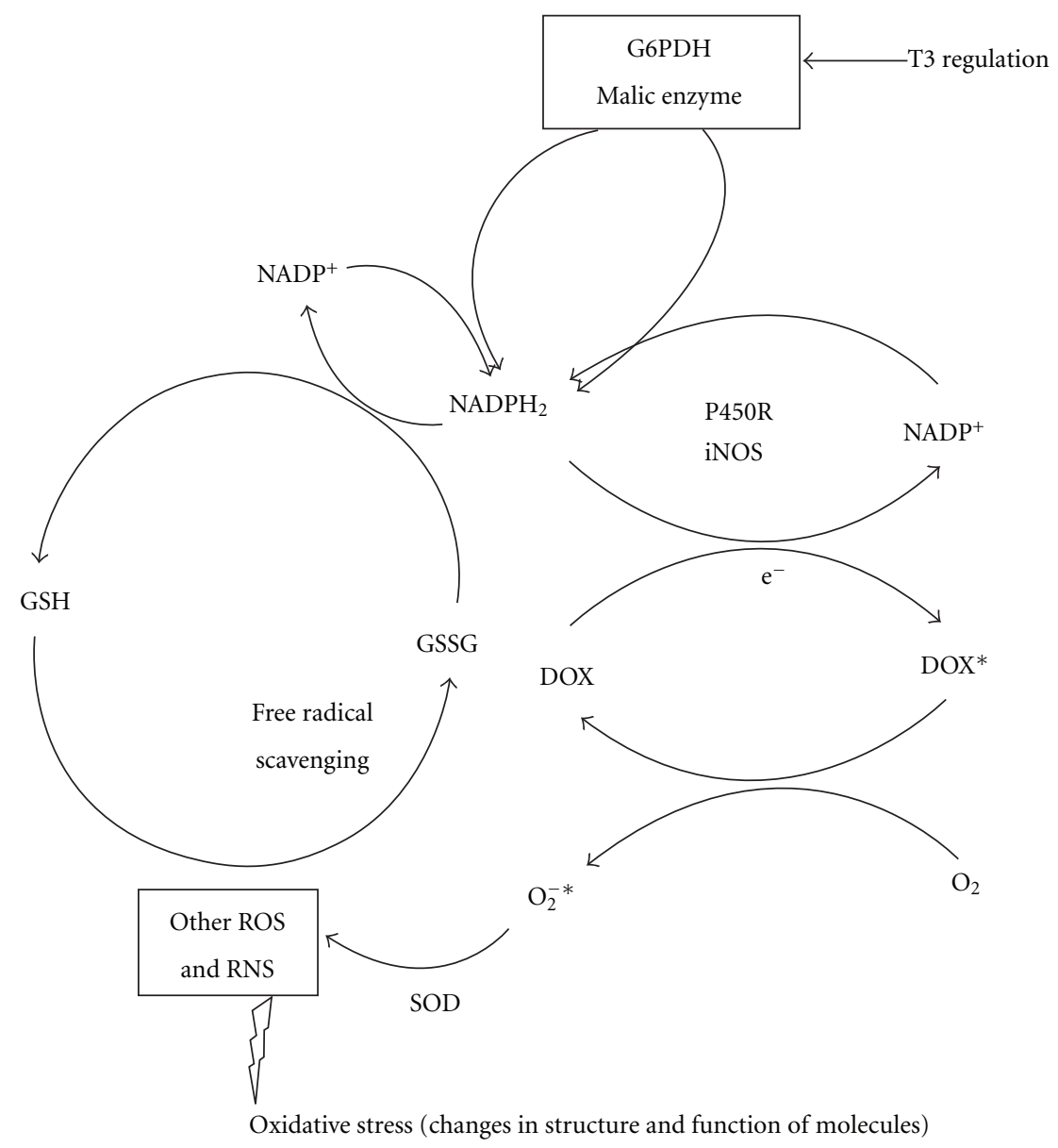

FIGURE 1: Mechanism expressed doxorubicin-dependent free radical generation and reportedly proposed role of triiodothyronine in redox equilibrium. P450R and iNOS transfer one electron to doxorubicin (DOX) from $\mathrm{NADPH}_{2}$ leading to synthesis of doxorubicin radical $\left(\mathrm{DOX}^{*}\right)$. Subsequently, electron is taken by $\mathrm{O}_{2}$ and to produce superoxide anion radical $\left(\mathrm{O}_{2}{ }^{-*}\right)$. That is staring point to oxidative stress. Seemingly paradoxically $\mathrm{NADPH}_{2}$ is indispensable to antioxidative activity, and its synthesis is transcriptionally regulated by triiodothyronine (T3).

species [9]. In those conditions, oxidation of lipids, protein, and DNA or nitration of amino acids of enzymes may appear [10]. Among enzymes affected by nitration, there is superoxide dismutase, a key enzyme of antioxidative defence [11].

The oxidative stress in cardiomyocytes triggered by doxorubicin is initiated by one-electron reduction, catalyzed mainly by microsomal cytochrome P450 NADPH-reductase (P-450R) [12, 13], nitric oxide synthases (NOS) [14], cytosolic xanthine oxidase (XO) $[15,16]$, and mitochondrial NADH dehydrogenase [17].

Interestingly, the animal and human data indicates that triiodothyronine (T3) - an active metabolite of thyroxine (T4) - upregulates P450R synthesis [18-20]. A similar mechanism has been suggested for thyroxine in case of iNOS [21]. Moreover, thyroxine regulates the crucial enzymes responsible for synthesis of NADPH - a cofactor for both P450R and iNOS and seemingly paradoxically the key factor in cellular redox balance (Figure 1 ).

The aim of the study was to evaluate the effect of hypothyreosis on the oxidative stress induced by doxorubicin and to estimate the effect of both hypothyreosis and the drug on P450 and iNOS protein level.

\section{Materials and Methods}

2.1. Animals and Treatment. The study was approved by the Local Ethical Committee at the Medical University of Lublin. Male Wistar rats (180-220 g) were kept under conventional laboratory conditions (temperature $22^{\circ} \mathrm{C}$, humidity $60-70 \%$, 12 hours light/dark cycle) and fed with standard rodent granulated fodder LSM (AGROPOL, Poland). Food and water were freely available. The rats were randomly divided into groups, and each group contained seven subjects. The rats received thyreostatic drug-methimazole (methizole; ICN, Poland) in drinking water for three weeks at two concentrations ( 0.001 or $0.025 \%$; group $\mathrm{MET}_{\mathrm{L}}$ or $\mathrm{MET}_{\mathrm{H}}$, resp.). For the remaining time of the experiment, only filtrate municipal water was administered. 48 hours after completing methimazole administration, the rats received doxorubicin 
(EBEWE Arzneimittel Ges.m.b.H., Austria) at the concentrations of $2.0,5.0$, and $15 \mathrm{mg} / \mathrm{kg}$ of the body weight (groups $2 \mathrm{DOX}+\mathrm{MET}_{\mathrm{L}}, 5 \mathrm{DOX}+\mathrm{MET}_{\mathrm{L}}, 15 \mathrm{DOX}+\mathrm{MET}_{\mathrm{L}}$ and 2DOX $+\mathrm{MET}_{\mathrm{H}}, 5 \mathrm{DOX}+\mathrm{MET}_{\mathrm{H}}, 15 \mathrm{DOX}+\mathrm{MET}_{\mathrm{H}}$ ). Doxorubicin hydrochloric was dissolved $(1: 1 ; \mathrm{v} / \mathrm{v})$ in a saline solution (Cefarm, Poland). The other groups were exposed exclusively to doxorubicin but without inducing hypothyreosis (groups 2DOX, 5DOX, and 15DOX). The biological materials (blood and hearts) were collected 4, 48, and 96 hours after doxorubicin administration. In groups $\mathrm{MET}_{\mathrm{L}}$ and $\mathrm{MET}_{\mathrm{H}}, 48$ hours after cessation of methimazole, rats were administered with saline, and, after the next 96 hours, the biological material was collected for further biochemical analyses. A similar procedure was applied in control group, in which 96 hours after the saline injection the rats were sacrificed.

The blood was aspirated from the left ventricle during the pentobarbital anaesthesia, and the obtained plasma was kept at $-75^{\circ} \mathrm{C}$. Immediately afterwards, the heart was removed during autopsy, washed with $20 \mathrm{~mL}$ of saline, and sectioned along the interventricular and coronal groves. The wall of the left ventricle was placed in a liquid nitrogen and stored at $-75^{\circ} \mathrm{C}$ until the biochemical and molecular analysis. The right ventricular wall was fixed in the buffered $10 \%$ formalin and routinely histologically processed to paraffin blocks.

\subsection{Determination of Biochemical Parameters}

2.2.1. Serum Triiodothyronine and Tetraiodothyronine. Triiodothyronine $\left(\mathrm{FT}_{3}\right)$ and tetraiodothyronine $\left(\mathrm{FT}_{4}\right)$ concentrations in rat plasma were measured using commercial reagents (AxSYM; Abbott, USA). The sample and antibodycoated microparticles added with reagent form an antibodyantigen complex. The T3 or T4 alkaline phosphatase conjugate binds to the available site on the anti- $\mathrm{T}_{3}\left(\right.$ anti- $\left.\mathrm{T}_{4}\right)$ coated microparticles. Finally, 4-methylumbelliferyl phosphate was added and the fluorescent intensiveness of the obtained product was measured.

2.2.2. Determination of Tissue Markers for Redox Imbalance. All measurements were conducted on homogenates obtained from $\sim 200 \mathrm{mg}$ of frozen cardiac samples using the extraction buffer provided by the manufacturer of each commercial kit and homogeniser with teflon pistil (Glas-Col, USA). Plate reader PowerWave XS (Bio-tek, USA), was used to assess oxidative product of lipids (as a sum malondialdehyde and 4-hydroxyalkenals), proteins (carbonyl groups), DNA (basic sites), and the total glutathione.

2.2.3. Lipid Peroxidation Products. The evaluation of lipid peroxidation in cardiac homogenates was based on malondialdehyde and 4-hydroxyalkenals concentration (MDA + 4HAE). The commercial kit Biotech LPO-586 for MDA + 4HAE (OxisResearch, USA) was used for the assessment. The concept of the method is based on the reaction between MDA and 4HAE with $\mathrm{N}$-methyl-2-phenylindol. After mixing $\mathrm{N}$ methyl-2-phenylindole and methanol with the supernatant acquired from the homogenization, methanesulfonic acid was added and all reagents were placed at the temperature $45^{\circ} \mathrm{C}$ for 60 minutes. Next, the solution was centrifuged and the supernatant containing the product was transferred to the plastic plate used in the spectrophotometric reader PowerWave XS (BioTek USA) at $586 \mathrm{~nm}$. Subsequently, the procedure was conducted according to the manufacturer's description, and the concentration of MDA $+4 \mathrm{HNE}$ in the tested samples was calculated from the formula of the calibration curve $y=0.0896 x-0.008$. The obtained date was calculated taking into account recommendations described in the procedure. The obtained results were expressed in $\mathrm{nm} / \mathrm{g}$ of cardiac sample.

2.2.4. Protein Carbonyl Groups. Determination of protein carbonyl groups was conducted using the commercial kit (Cayman's Protein Carbonyl Assay; Cayman, USA). The obtained supernatant absorbance was checked at 260 and $280 \mathrm{~nm}$ to determine if the contaminating nucleic acid is present in the sample. The homogenisation buffer was used as a blank. The absorbance ratio 280/260 was more than 1.0; thus, the further step to remove nucleic acid was not necessary. The methods utilize the reaction of protein carbonyl groups with 2,4-dinitrofenylhydrazyne. The product of the reaction was measured at $360 \mathrm{~nm}$. The concentration of the carbonyl group was standardised on the protein unit (nmol carbonyl group/mg protein). The amount of protein was calculated from the bovine serum albumin dissolved in guanidine hydrochloride and read at $280 \mathrm{~nm}$.

2.2.5. DNA Oxidative Damage. The commercial kit for isolation of genomic DNA (Fermentas, Lithuania) was used for isolation of the cardiac DNA according to the manufacturer's manual. The frozen cardiac sample was pulverized in liquid nitrogen and suspended in TRIS-EDTA buffer. Then, the sample was incubated in a lysis buffer at $65^{\circ} \mathrm{C}$. Released DNA was extracted with the use of chloroform and then precipitated with a precipitation factor. DNA oxidative damage in cardiac muscles was evaluated by measuring the amount of basic sites (the so called AP) with a commercial kit (Dojindo, Japan). Isolated DNA was labeled with ARP reagent which can recognize the aldehyde group of the open ring in AP sites and can combine with biotin. Then, biotinavidin specific connection and horseradish peroxidase were used for the colorimetric detection at $650 \mathrm{~nm}$.

2.2.6. Total Glutathione. Glutathione determination was conducted using a commercial kit Bioxytech GSH/GSSG412 (OxisResearch, USA). The total glutathione $\left(\mathrm{GSH}_{\mathrm{t}}\right.$; GSH (reduced glutathione) + GSSG (oxidized glutathione) was determined in the enzymatic reaction, where Ellman's reagent (5,5'-dithio-bis-2-nitrobenzoic acid) reacts with GSH forming color product with the maximum of absorbance at $412 \mathrm{~nm}$. The concentrations of GSH, GSSG, and GSH/GSSG ratio were assessed after measuring the speed of the reaction and establishing calibrations curves. Concentrations of GSH and GSSG were determined based on the calibration curve described by the following formula: 
$y=0.1447 x+0.0004$ and $y=0.1475 x$, respectively. The obtained data was used to calculate the GSH/GSSG ratio.

2.3. Xanthine Oxidase Activity. The determination of xanthine oxidase activity (XO, EC 1.1.3.22) in the heart homogenates was conducted on the basis of the kinetic reaction of transformation xanthine to uric acid (Sigma Aldrich, USA) [22]. The increase of absorbance per unit of time at $290 \mathrm{~nm}$ was measured using a spectrophotometric reader PowerWave XT (BioTek, USA) at the light path $1 \mathrm{~cm}$, at $25^{\circ} \mathrm{C}$ and $\mathrm{pH} 7.5$. The absorbance was recorded every minute during 5 minutes. The phosphate buffet ( $\mathrm{pH} 7.5$ ) was added to the blank instead of the supernatant. The calculated enzyme activity was expressed on the mass unit of the sample of heart.

\subsection{Molecular Analysis}

2.4.1. Cytochrome P450 NADPH-Reductase. The content of cytochrome P450 NADPH-reductase (E.C. 1.6.2.4) protein was measured using WesternBreeze chromogenic Western Blot immunodetection kit (Invitrogen, USA). The left ventricular sample was homogenized in a phosphate-buffered saline with protease inhibitor cocktail (Sigma). After $30 \mathrm{~min}$ of blocking the nonspecific binding sites, the nitrocellulose membrane was incubated for $1 \mathrm{~h}$ with a rabbit antirat cytochrome $\mathrm{P} 450$ reductase polyclonal antibody (QED Bioscencie) (1:1000) followed by a $30 \mathrm{~min}$ incubation with an alkaline phosphatase-conjugated anti-rabbit IgG secondary antibody. Immunoblots were developed using chromogenic substrate for $10 \mathrm{~min}$, and the membrane was airdried overnight. The chromogenic substrate was a mixture of BCIP (5-bromo-4-chloro-3-indolyl phosphate) and nitroblue tetrazolium salt.

2.4.2. Immunoexpression of iNOS. Immunohistochemical reaction for inducible nitric oxide synthase (iNOS; E.C. 1.14.13.39) was performed on the $4 \mu \mathrm{m}$ slides obtained from the paraffin blocks. After dewaxing and rehydration, the slides were placed for three cycles of heating in a microwave oven $(750 \mathrm{~W})$ for $5 \mathrm{~min}$ in the citrate buffer $(0.01 \mathrm{M}, \mathrm{pH}$ 6.0) for antigen retrieval. Then, endogenous peroxidase activity was blocked with $3 \%$ hydrogen peroxide for $5 \mathrm{~min}$, and the slides were incubated for $60 \mathrm{~min}$ with the primary polyclonal rabbit anti-mouse antibodies (LabVision, USA) against iNOS (clone Ab-1, dilution 1:50). The next step was the incubation with DakoEnvision+/HRP, Mouse kit (DakoCytomation; Glostrup, Denmark) according to the manufacturer's directions. The specific immune reaction was visualized by $3^{\prime}, 3$-diaminobenzidine tetrahydrochloride (DAB) (DakoCytomation; Glostrup, Denmark), and finally the sections were counterstained with Mayer's hematoxylin. TBS buffer rinsing was used after each step. The whole procedure was performed at room temperature. In all cases, the appropriate positive and negative controls were performed. The sections were treated in the same way, but with mouse preimmune serum except that examined primary antibodies were used as negative controls. For the positive control, the rat lung sample was applied. All slides were eval- uated, without the knowledge of the treated group, under light microscope (Olympus BX45; Tokyo, Japan).

2.5. Statistical Analysis. The obtained data were analysed using STATISTICA 5.0. (Statsoft Inc., USA). Statistical significance was evaluated by $U$ Mann-Witney test (versus saline control) and by one-way analysis of variance (ANOVA Kruskala-Wallisa). The post hoc test (Newmana-Keulsa) was used to verify null hypothesis, according to which the lowered thyroid hormones status influence the evaluated parameters. All data are expressed as mean $\pm \mathrm{SD}$. The value of $P<0.05$ was considered statistically significant.

\section{Results}

The average plasma FT4 and FT3 concentrations of animals receiving methimazole in a lower dosage were significantly lower in comparison to the control subjects (Table 1). In the group exposed to higher drug concentration, both parameters were below the level of detection.

Comparing to the control, higher levels of MDA $+4 \mathrm{HNE}$ were observed in groups $15 \mathrm{DOX} / 96 \mathrm{~h}, 15 \mathrm{DOX}+\mathrm{MET}_{\mathrm{H}} / 48 \mathrm{~h}$, and $15 \mathrm{DOX}+\mathrm{MET}_{\mathrm{H}} / 96 \mathrm{~h}$ (Table 2). Unexpectedly, group $\mathrm{MET}_{\mathrm{L}}$ diminished MDA $+4 \mathrm{HNE}$ concentration $96 \mathrm{~h}$ after doxorubicin administration ( $2 \mathrm{mg} / \mathrm{kg}$ ) comparing to the proper group of DOX. Doxorubicin as a single agent applied in the highest dose significantly increased carbonyl groups concentration in animals after 4, 48, and 96 hours (Table 3). Statistically significant differences were also found between the carbonyl groups concentrations in euthyroid and hypothyroid rats receiving doxorubicin. Comparing to respective DOX group, significantly higher values were observed when doxorubicin was given to rats receiving the earlier higher dose of methimazole. Similar variables were noted for the middle and highest doses of doxorubicin, when, before the administration of the drug animals, were pretreated with a lower dose of methimazole. However, significantly lower concentrations of the carbonyl groups occurred in $15 \mathrm{DOX}+\mathrm{MET}_{\mathrm{L}}$.

After the administration of the middle dose of doxorubicin, the amount of oxidative damage in DNA was rising significantly at 4 and 48 hours comparing to control (Table 4). The highest tested dose of doxorubicin triggered a significant increase in DNA damage in all tested periods. Similar changes comparing to control were observed in almost every comparable hypothyroid-like group administered with doxorubicin. However, significant changes were not revealed between any DOX + MET and DOX pairs.

The total glutathione concentration was not affected in any groups exposed to doxorubicin only when compared to the control (Table 5). However, a substantial increase of the parameter at 48 hours was observed when animals were pretreated with methimazole before the administration of the middle and highest doses of doxorubicin. Interestingly, the changes in $\mathrm{GSH}_{\mathrm{T}}$ in rats receiving doxorubicin were related to the stage of hypothyreosis. A increase in 5DOX + $\mathrm{MET}_{\mathrm{L}} / 96 \mathrm{~h}$ and a decrease in $5 \mathrm{DOX}+\mathrm{MET}_{\mathrm{H}} / 96$ were observed when compared with the control. Importantly, this 
TABLE 1: The concentration (pmol/L; $X \pm$ S.D.) of free tetraiodothyronine (FT4) and triiodothyronine (FT3) in rats serum $48 \mathrm{~h}$ after withdrawal of methimazole.

\begin{tabular}{lccc}
\hline & Methimazole $(\%)$ & \\
& 0.000 & $0.001\left(\mathrm{MET}_{\mathrm{L}}\right)$ & $0.025\left(\mathrm{MET}_{\mathrm{H}}\right)$ \\
\hline FT4 & $10.48 \pm 1.12$ & $6.10 \pm 1.55(P=0.0009)$ & Below limit of detection $(<2.60)$ \\
FT3 & $3.52 \pm 0.49$ & $2.39 \pm 0.57(P=0.0092)$ & Below limit of detection $(<1.67)$ \\
\hline
\end{tabular}

TABLE 2: Malonyldialdehyd and 4-hydroxynonenal concentration (nmol/g of cardiac sample; $X \pm$ S.D.) in rat cardiac homogenates 4,48 , and $96 \mathrm{~h}$ after doxorubicin administration.

\begin{tabular}{|c|c|c|c|c|c|}
\hline \multirow{2}{*}{ Time from DOX injection (h) } & \multirow{2}{*}{ DOX $(\mathrm{mg} / \mathrm{kg})$ or saline } & \multicolumn{3}{|c|}{ Methimazole (\%) } & \multirow{2}{*}{$\begin{array}{c}\text { ANOVA } \\
P\end{array}$} \\
\hline & & 0.0000 & $0.001\left(\mathrm{MET}_{\mathrm{L}}\right)$ & $0.025\left(\mathrm{MET}_{\mathrm{H}}\right)$ & \\
\hline \multirow{3}{*}{4} & 2 & $28.01 \pm 3.07$ & $30.33 \pm 4.06$ & $29.12 \pm 4.73$ & 0.6977 \\
\hline & 5 & $30.36 \pm 2.52$ & $31.42 \pm 3.58$ & $26.11 \pm 3.82$ & 0.0706 \\
\hline & 15 & $31.81 \pm 3.67$ & $35.21 \pm 7.40$ & $33.93 \pm 4.09$ & 0.7163 \\
\hline \multirow{3}{*}{48} & 2 & $25.84 \pm 4.26$ & $23.37 \pm 3.94$ & $22.01 \pm 4.14$ & 0.5945 \\
\hline & 5 & $26.85 \pm 1.39$ & $25.06 \pm 3.90$ & $25.84 \pm 0.96$ & 0.6288 \\
\hline & 15 & $29.85 \pm 6.50$ & $29.63 \pm 7.85$ & $38.50 \pm 4.5^{*}$ & 0.7520 \\
\hline \multirow{4}{*}{96} & 2 & $31.36 \pm 10.45$ & $22.43 \pm 1.99^{\#}$ & $28.49 \pm 4.83$ & 0.0358 \\
\hline & 5 & $31.25 \pm 4.33$ & $32.20 \pm 7.48$ & $26.12 \pm 4.93$ & 0.2535 \\
\hline & 15 & $39.36 \pm 3.39^{*}$ & $35.43 \pm 4.38$ & $44.99 \pm 13.87^{*}$ & 0.2783 \\
\hline & $0.9 \% \mathrm{NaCl}$ & $24.89 \pm 6.71$ (control) & $26.32 \pm 3.24$ & $22.48 \pm 3.42$ & - \\
\hline
\end{tabular}

${ }^{*} P<0.05$ versus control; ${ }^{*}$ DOX + MET versus DOX.

TABLE 3: Carbonyl group concentration (nmol/mg of of cardiac protein; $X \pm$ S.D.) in rat cardiac homogenates 4,48 , and $96 \mathrm{~h}$ after doxorubicin administration.

\begin{tabular}{|c|c|c|c|c|c|}
\hline \multirow{2}{*}{ Time from DOX injection (h) } & \multirow{2}{*}{ DOX $(\mathrm{mg} / \mathrm{kg})$ or saline } & \multicolumn{3}{|c|}{ Methimazole (\%) } & \multirow{2}{*}{$\begin{array}{c}\text { ANOVA } \\
P\end{array}$} \\
\hline & & 0.0000 & $0.001\left(\mathrm{MET}_{\mathrm{L}}\right)$ & $0.025\left(\mathrm{MET}_{\mathrm{H}}\right)$ & \\
\hline \multirow{3}{*}{4} & 2 & $19.55 \pm 5.12$ & $28.18 \pm 6.11^{*, \#}$ & $45.45 \pm 16.15^{*, \#, \dagger}$ & 0.0098 \\
\hline & 5 & $19.41 \pm 9.41$ & $38.65 \pm 13.45^{*, \#}$ & $103.08 \pm 46.03^{*, \#, \dagger}$ & 0.0050 \\
\hline & 15 & $57.52 \pm 16.05^{*}$ & $20.08 \pm 7.59^{\#}$ & $75.77 \pm 14.25^{*, \#}$ & 0.0060 \\
\hline \multirow{3}{*}{48} & 2 & $18.92 \pm 5.30$ & $29.46 \pm 6.92^{*, \#}$ & $42.75 \pm 12.46^{*, \#}$ & 0.0098 \\
\hline & 5 & $21.29 \pm 6.62$ & $40.43 \pm 22.04^{*, \#}$ & $109.95 \pm 84.48^{*, \#}$ & 0.0063 \\
\hline & 15 & $54.73 \pm 1434^{*}$ & $14.70 \pm 6.57^{\#}$ & $124.24 \pm 62.84^{*, \#}$ & 0.0045 \\
\hline \multirow{4}{*}{96} & 2 & $15.39 \pm 4.24$ & $28.49 \pm 10.61^{*, \#}$ & $37.21 \pm 6.67^{*, \#}$ & 0.0081 \\
\hline & 5 & $15.05 \pm 4.30$ & $19.51 \pm 4.37^{\#}$ & $89.22 \pm 42.42^{*, \#, \dagger}$ & 0.0052 \\
\hline & 15 & $39.30 \pm 10.14^{*}$ & $15.06 \pm 4.98^{\#}$ & $91.76 \pm 56.76^{*, \#, \dagger}$ & 0.0025 \\
\hline & $0.9 \% \mathrm{NaCl}$ & $17.68 \pm 5.92($ control $)$ & $17.87 \pm 3.35$ & $20.87 \pm 4.29$ & - \\
\hline
\end{tabular}

${ }^{*} P<0.05$ versus control; ${ }^{\#} \mathrm{DOX}+\mathrm{MET}$ versus DOX; ${ }^{\dagger} \mathrm{DOX}+\mathrm{MET}_{\mathrm{H}}+$ versus $\mathrm{DOX}+\mathrm{MET}_{\mathrm{L}}$.

TABLE 4: The amount of oxidative damages of DNA (for $10^{6}$ base pairs; $X \pm$ S.D.) in rat cardiac homogenates 4 , 48 , and $96 \mathrm{~h}$ after doxorubicin administration.

\begin{tabular}{|c|c|c|c|c|c|}
\hline \multirow{2}{*}{ Time from DOX injection $(\mathrm{h})$} & \multirow{2}{*}{ DOX $(\mathrm{mg} / \mathrm{kg})$ or saline } & \multicolumn{3}{|c|}{ Methimazole (\%) } & \multirow{2}{*}{$\begin{array}{c}\text { ANOVA } \\
P\end{array}$} \\
\hline & & 0.0000 & $0.001\left(\mathrm{MET}_{\mathrm{L}}\right)$ & $0.025\left(\mathrm{MET}_{\mathrm{H}}\right)$ & \\
\hline \multirow{3}{*}{4} & 2 & $1.22 \pm 0.14$ & $1.16 \pm 0.11$ & $1.23 \pm 0.11$ & 0.4706 \\
\hline & 5 & $1.54 \pm 0.21^{*}$ & $1.26 \pm 0.12^{*}$ & $1.60 \pm 0.22^{*, \dagger}$ & 0.0478 \\
\hline & 15 & $1.82 \pm 0.17^{*}$ & $1.64 \pm 0.17^{*}$ & $1.90 \pm 0.31^{*}$ & 0.2645 \\
\hline \multirow{3}{*}{48} & 2 & $1.13 \pm 0.05$ & $1.14 \pm 0.07$ & $1.12 \pm 0.04$ & 0.8670 \\
\hline & 5 & $1.21 \pm 0.07^{*}$ & $1.14 \pm 0.06$ & $1.29 \pm 0.03^{*, \dagger}$ & 0.0183 \\
\hline & 15 & $1.55 \pm 0.13^{*}$ & $1.38 \pm 0.15^{*}$ & $1.63 \pm 0.17^{*}$ & 0.0517 \\
\hline \multirow{4}{*}{96} & 2 & $1.11 \pm 0.06$ & $1.10 \pm 0.05$ & $1.10 \pm 0.04$ & 0.9900 \\
\hline & 5 & $1.15 \pm 0.35$ & $1.10 \pm 0.03$ & $1.23 \pm 0.09^{*, \dagger}$ & 0.0271 \\
\hline & 15 & $1.35 \pm 0.13^{*}$ & $1.29 \pm 0.08^{*}$ & $1.38 \pm 0.06^{*}$ & 0.2645 \\
\hline & $0.9 \% \mathrm{NaCl}$ & $1.10 \pm 0.05$ (control) & $1.13 \pm 0.06$ & $1.11 \pm 0.06$ & \\
\hline
\end{tabular}

${ }^{*} P<0.05$ versus control; ${ }^{\dagger} \mathrm{DOX}+\mathrm{MET}_{\mathrm{H}}$ versus $\mathrm{DOX}+\mathrm{MET}_{\mathrm{L}}$. 
TABLE 5: Total glutathione concentration (nmol/g of cardiac sample; $X \pm$ S.D.) in rat cardiac homogenates 4,48 , and $96 \mathrm{~h}$ after doxorubicin administration.

\begin{tabular}{|c|c|c|c|c|c|}
\hline \multirow{2}{*}{ Time from DOX injection (h) } & \multirow{2}{*}{ DOX $(\mathrm{mg} / \mathrm{kg})$ or saline } & \multicolumn{3}{|c|}{ Methimazole (\%) } & \multirow{2}{*}{$\begin{array}{c}\text { ANOVA } \\
P\end{array}$} \\
\hline & & 0.0000 & $0.001\left(\mathrm{MET}_{\mathrm{L}}\right)$ & $0.025\left(\mathrm{MET}_{\mathrm{H}}\right)$ & \\
\hline \multirow{3}{*}{4} & 2 & $369.27 \pm 29.45$ & $353.04 \pm 30.24$ & $363.68 \pm 37.97$ & 0.6505 \\
\hline & 5 & $405.83 \pm 77.76$ & $356.66 \pm 26.28$ & $394.16 \pm 39.15$ & 0.3356 \\
\hline & 15 & $348.33 \pm 22.55$ & $418.33 \pm 52.50$ & $363.33 \pm 39.46$ & 0.0514 \\
\hline \multirow{3}{*}{48} & 2 & $361.54 \pm 43.76$ & $395.52 \pm 31.92$ & $378.85 \pm 29.82$ & 0.4449 \\
\hline & 5 & $353.33 \pm 70.73$ & $454.16 \pm 46.68^{*, \#}$ & $455.83 \pm 41.10^{*, \#}$ & 0.0418 \\
\hline & 15 & $395.83 \pm 69.53$ & $564.16 \pm 72.08^{*, \#}$ & $439.17 \pm 16.82^{*, \#, \dagger}$ & 0.0080 \\
\hline \multirow{4}{*}{96} & 2 & $339.16 \pm 43.16$ & $328.33 \pm 27.54$ & $362.50 \pm 35.84$ & 0.2101 \\
\hline & 5 & $340.00 \pm 31.54$ & $421.66 \pm 49.07^{*}$ & $300.83 \pm 62.04^{*, \#, \dagger}$ & 0.0081 \\
\hline & 15 & $322.92 \pm 55.54$ & $367.71 \pm 34.42$ & $365.00 \pm 38.14$ & 0.3813 \\
\hline & $0.9 \% \mathrm{NaCl}$ & $368.33 \pm 34.43$ (control) & $342.71 \pm 83.57$ & $395.83 \pm 25.68$ & - \\
\hline
\end{tabular}

${ }^{*} P<0.05$ versus control; ${ }^{\#} \mathrm{DOX}+\mathrm{MET}$ versus DOX; ${ }^{\dagger} \mathrm{DOX}+\mathrm{MET}_{\mathrm{H}}$ versus $\mathrm{DOX}+\mathrm{MET}_{\mathrm{L}}$.

TABle 6: Xanthine oxidase activity ( $\mu \mathrm{U} / \mathrm{g}$ of cardiac sample; $X \pm$ S.D.) in rat cardiac homogenates 4 , 48 , and $96 \mathrm{~h}$ after doxorubicin administration.

\begin{tabular}{lccccc}
\hline $\begin{array}{l}\text { Time from DOX } \\
\text { injection }(\mathrm{h})\end{array}$ & Dose of DOX $(\mathrm{mg} / \mathrm{kg}$ b.w. $)$ & Methimazole & \multicolumn{1}{c}{ ANOVA } \\
\hline \multirow{4}{*}{4} & 2 & 0.0000 & $0.001 \%$ & $0.025 \%$ \\
& 5 & $52.00 \pm 14.00$ & $56.00 \pm 17.10$ & $47.00 \pm 18.00$ & 0.6229 \\
& 15 & $43.00 \pm 8.00$ & $43.00 \pm 14.50$ & $47.00 \pm 18.60$ & 0.9680 \\
48 & 2 & $57.00 \pm 8.00$ & $34.00 \pm 2.90^{*, \#}$ & $101.00 \pm 6.91^{\#, \dagger}$ & 0.0171 \\
\hline & 5 & $38.00 \pm 17.10$ & $56.00 \pm 14.30$ & $54.00 \pm 16.60$ & 0.1998 \\
& 15 & $34.00 \pm 10.60$ & $66.00 \pm 50.00$ & $64.00 \pm 17.4$ & 0.0602 \\
96 & 2 & $65.00 \pm 37.00$ & $54.00 \pm 9.40$ & $58.00 \pm 15.7$ & 0.9324 \\
\hline & 5 & $50.00 \pm 16.80$ & $67.00 \pm 19.00$ & $55.00 \pm 24.6$ & 0.3705 \\
& 15 & $54.00 \pm 32.70$ & $60.00 \pm 10.90$ & $49.00 \pm 18.00$ & 0.3724 \\
& $0.9 \% \mathrm{NaCl}$ & $68.00 \pm 33.60$ & $52.00 \pm 7.10$ & $60.00 \pm 12.60$ & 0.6057 \\
\hline
\end{tabular}

${ }^{*} \mathrm{P}<0.05$ versus control; ${ }^{\#} \mathrm{DOX}+\mathrm{MET}$ versus DOX; ${ }^{\dagger} \mathrm{DOX}+\mathrm{MET}_{\mathrm{H}}$ versus $\mathrm{DOX}+\mathrm{MET}_{\mathrm{L}}$.

rise in $\mathrm{GSH}_{\mathrm{T}}$ level in rats with hypothyreosis receiving doxorubicin $\left(5,15 \mathrm{DOX}+\mathrm{MET}_{\mathrm{L}, \mathrm{H}} / 48\right)$ was also significant when compared to DOX group.

The activity of xanthine oxidase in the heart muscle of the rats receiving doxorubicin was not affected when compared with control groups (Table 6). However, in groups 15DOX + $\mathrm{MET}_{\mathrm{L}} / 4 \mathrm{~h}$ and $15 \mathrm{DOX}+\mathrm{MET}_{\mathrm{H}} / 4 \mathrm{~h}$, respectively, lower and higher activity of the studied enzyme was found in relation to the observed values in the DOX group. Lack of differences in protein P450R expression using Western Blot technique was observed in the cardiac muscle among animals receiving doxorubicin alone when compared with the control group (Figure 2). On the contrary, the expression of protein was higher in groups of rats administered with a lower dose of methimazole with all tested doses of doxorubicin versus control and DOX groups. However, in all DOX groups receiving a higher dose of methimazole, insignificant changes were observed comparing to control and DOX groups as well.

A diffuse cytoplasmic immunostaining for iNOS and higher iNOS gene expression was found in the cardiac muscle, especially in the group examined at 96 hours and exposed exclusively to the lowest and middle doses of doxorubicin (Figures 3 and 4). In case of animals exposed to doxorubicin with previously induced hypothyreosis, the level of iNOS mRNA and protein was lower and comparable to the control.

\section{Discussion}

The conducted study revealed that hypothyreosis had an important effect on the cardiac oxidative stress in rats exposed to doxorubicin. The direction of these changes was dependent on the concentration of iodothyronine hormones and the cytostatic dose. In case of hypothyreosis, the intensity of the doxorubicin-dependent oxidative stress was not related to the P450R, iNOS, and OX level.

The oxidative stress in cardiomyocytes triggered by doxorubicin is a widely accepted hypothesis in cardiotoxicity leading to the fatal congestive failure of the heart. As it was pointed above (Figure 1), the one-electron doxorubicin reduction, a key process in oxidative stress development, is catalyzed by microsomal $[12,13]$, cytoplasmic $[12,14,15]$, and mitochondrial enzymes [17]. Among microsomal and 


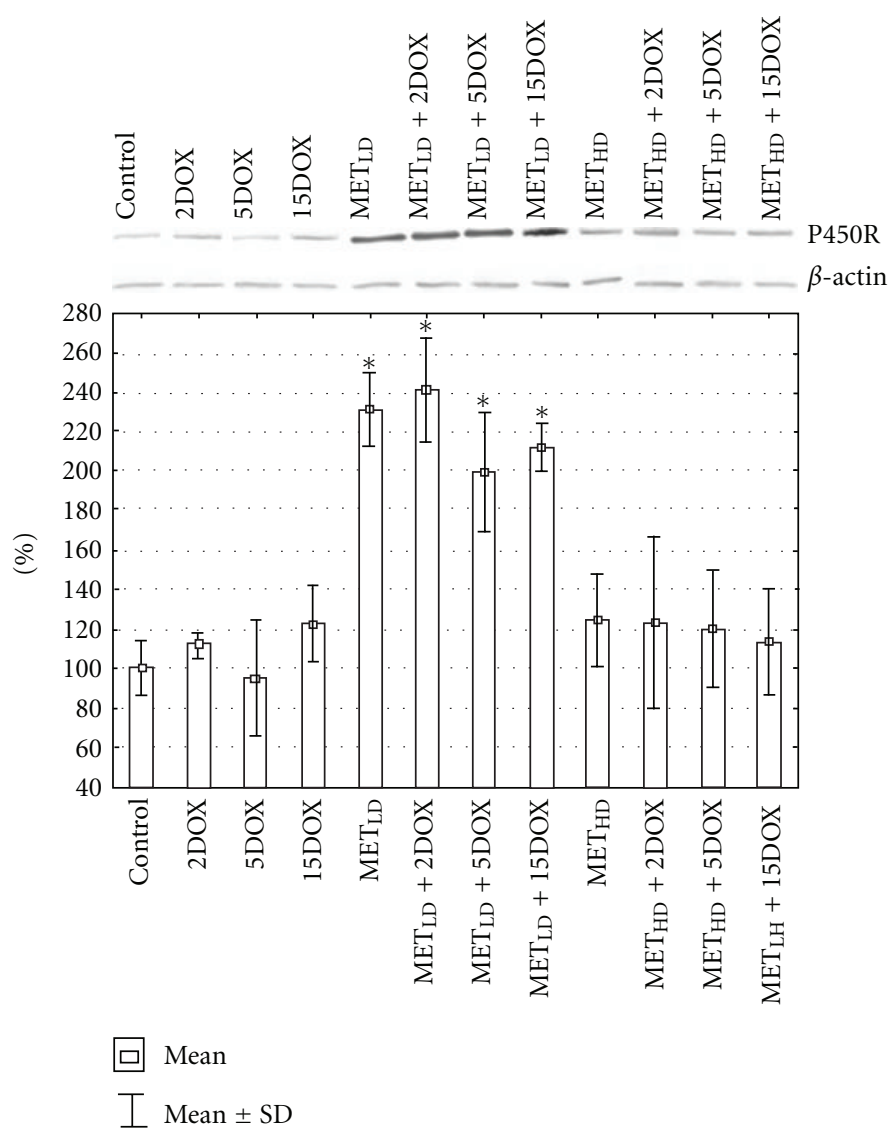

Figure 2: Representative Western Blot analysis for P450R protein in cardiac muscle homogenates. Beta-actin is shown as a loading control. Densitometric analysis (mean \pm SD) of total P450R content, expressed as percent changes with respect to the control group, which has been set at $100 \%{ }^{*} P<0.05$ versus control and proper DOX group.



(a)

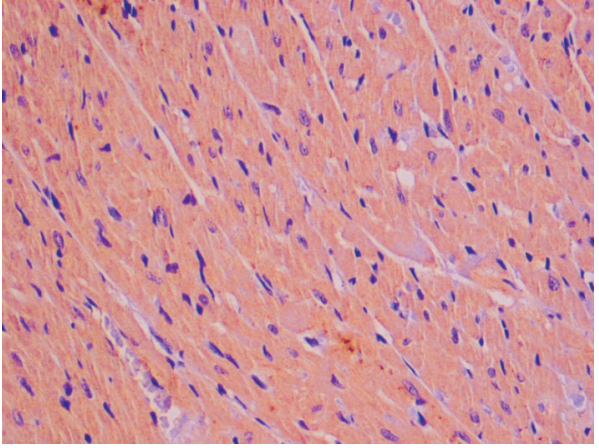

(b)

FIGURE 3: Strong positive cytoplasmic immunostaining for inducible nitric oxide synthase (iNOS) in cardiomyocytes. (a) 5DOX/96 h. (b) 5DOX $+\mathrm{MET}_{\mathrm{L}} / 96 \mathrm{~h}$; (DakoEnvision+/HRP; objective magnification (a) and (b): 20x).

cytoplasmic enzymes, the P450R [12, 13], iNOS [23, 24], and $\mathrm{XO}[15,16]$ play important role. As it was mentioned in the introduction, $\mathrm{T} 3$ and $\mathrm{T} 4$ via genome mechanism may change the activity of various enzymes engaged in doxorubicin redox activation $[18,20,21]$ and in antioxidative defence [19, 25-27].

To confirm the proper dose of methimazole, the plasma $\mathrm{FT}_{3}$ and $\mathrm{FT}_{4}$ was determined and thyroid histology (data not shown) was examined. The significant dose-dependent reduction of both $\mathrm{FT}_{3}$ and $\mathrm{FT}_{4}$ level and decreased amounts of colloid in thyroid follicles confirmed the properly chosen regiment of methimazole.

Clinical sensitivity of the analyzed oxidative stress markers varies in the order oxDNA > CG > MDA + 4HNE $>\mathrm{GSH}_{\mathrm{T}}$ since an increase in oxidative DNA damages was observed in all tested periods in the group of 15DOX and 


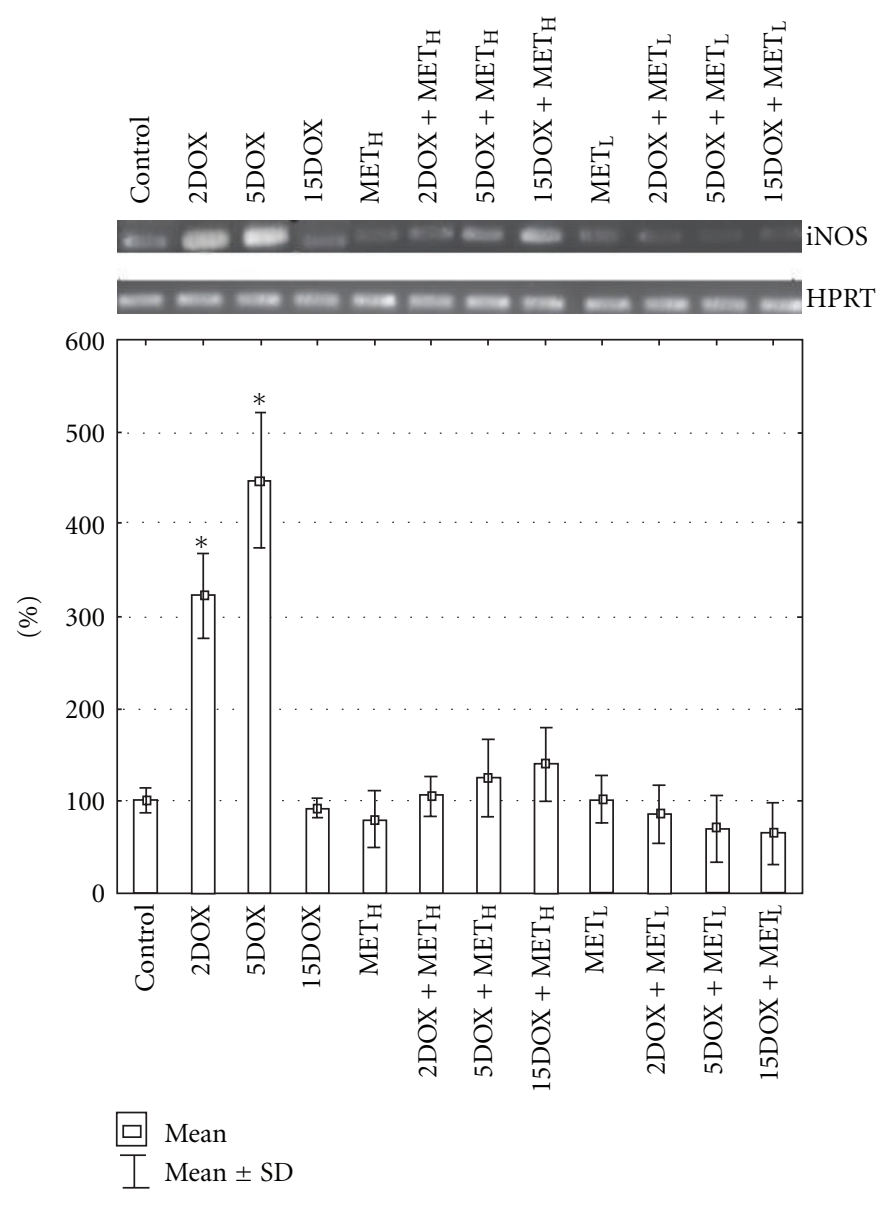

FIGURE 4: Representative mRNA iNOS content in cardiac muscle. HPRT was used as endogenous control. The results express percent changes (mean $\pm \mathrm{SD}$ ) with respect to the control group, which has been set at $100 \%$. ${ }^{*} P<0.05$ versus control.

after treatment with the middle dose of DOX $(5 \mathrm{mg})$ in 4 and $48 \mathrm{~h}$. A significant doxorubicin-dependent increase in CG concentration was also observed at 4,48 , and $96 \mathrm{~h}$ but only in groups administered with the highest dose of DOX. An important increase in the lipid peroxidation was revealed exclusively at $96 \mathrm{~h}$ from the administration of the highest doxorubicin dose. Moreover, a lack of the $\mathrm{GSH}_{\mathrm{T}}$ cardiac level changes was found.

Similar data was previously found in other studies. Palmeira et al. [28] observed that a single bolus of doxorubicin $(15 \mathrm{mg} / \mathrm{kg})$ caused a significant increase of the cardiac level of 8-hydroxydeoxyguanosine (8OHdG), another marker of DNA oxidative changes. The abundance of adducts was highest at the earliest time-point examined $(24 \mathrm{~h})$ and decreased to control values within 2 weeks. On the other hand, a significant increase in the level of the cardiac carbonyl group 10 days from single administration of doxorubicin in the dose of $20 \mathrm{mg}$ was also pointed out [29]. Moreover, the single doxorubicin dose in the range of $10-20 \mathrm{mg} / \mathrm{kg}$ caused an increase of lipid peroxidation products, which was revealed after several days from the drug injection [29-32], whereas a lower single dose of doxorubicin $(2.5 \mathrm{mg} / \mathrm{kg})$ caused an increase of MDA level during the first four hours and normalised within $24 \mathrm{~h}$ [33]. It seems that the dose of $2 \mathrm{mg}$, which was used in the current study, is too low to elicit a marked increase of the lipid peroxidation after single injection.

The question arises about the cause of different sensitivity determined markers after doxorubicin treatment. Based on the current knowledge, it is not possible to explain incompatible changes of various biochemical markers in case of the doxorubicin exposition. However, a biological halflife and sensitiveness to different kinds of reactive oxygen species should be considered. The carbonyl group appears relatively early and is stable during hours, and even days $[34,35]$, while the lifespan of the main lipid peroxidation products is estimated for minutes [36]. Lipid peroxidation products (e.g., MDA) form DNA adducts, which may explain the observed disproportion between the level of MDA and oxDNA in this study [37-40]. Moreover, oxidative destruction of lipids, protein, and DNA depends on the type of reactive oxygen species, for example, $\mathrm{HOCl}$, a product of the reaction catalysed by myeloperoxidase, easily elevates the carbonyl group concentration but has a very little or no activity to create oxidative changes in lipids and DNA in the intracellular environment [41]. It should be also stressed that 
in a study conducted by Fadillioglu et al. [29] a single dose of DOX $(20 \mathrm{mg} / \mathrm{kg})$ caused a significant increase of the cardiac myeloperoxidase activity.

It was previously assumed that hypothyreosis may change redox status in the heart of rats receiving doxorubicin, since triiodothyronine regulates P450R $[18,20]$ and is suspected to regulate iNOS expression [21], which plays an important role in bioreductive activation of DOX. Furthermore, the hormone upregulates the genes responsible for synthesis of G6PDH, malic enzyme, and 6-phosphogluconate dehydrogenase [27, 42]. These enzymes are a crucial cellular source of NADPH which via P450 and iNOS trigger ROS synthesis and, at the same time seemingly paradoxically, are indispensable in cell's antioxidative defence by reduced glutathione regeneration.

The current study revealed that hypothyroid conditions may increase the cardiac oxidative stress caused by doxorubicin. The most affected oxidative stress marker by hypothyreosis in rats treated with doxorubicin was CG. Similar result was also found for $\mathrm{GSH}_{\mathrm{T}}$ that was influenced by the lowest and middle doses of DOX at $48 \mathrm{~h}$ and in the lowest dose at $96 \mathrm{~h}$ after drug administration.

The significant influence of hypothyreosis on cardiac lipid peroxidation in rats administered with doxorubicin appears only one time, and no such changes were observed in the case of oxDNA damages. For that reason, the comments will be focused on changes in carbonyl groups.

After treatment with the lowest and middle doses of doxorubicin only, there were no significant changes in CG in any period of time comparing to the control. However, when both mentioned doses of the drug were given to rats with hypothyreosis, a significant increase of oxidative protein damages was revealed. That rise was even 2-3 times higher than in proper DOX group. In cases when rats were treated with doxorubicin only, oxidative protein damages were higher comparing to control in all periods of time. The protein oxidative damages in rats administered with the highest dose of the drug changed depending on hypothyreosis state. When doxorubicin was administered to the rats exposed to a lower methimazole concentration, the level of carbonyl groups dramatically dropped, but in animals with more intense hypothyreosis the carbonyl groups levels were significantly elevated.

The obtained finding referring to the $\mathrm{P} 450 \mathrm{R}$ protein level is somewhat surprising because referring to the assumption based on Ram and Waxman's [20] results, who observed that T3 upregulates gene expression of this enzyme, and on the basis of their study, it might be expected that inhibition of T3 synthesis caused by methimazole should diminish the concentration of the enzyme.

Taking into consideration that a very high increase in protein oxidative damages in all groups receiving the higher dose of methimazole with DOX was not accompanied by any changes in P450R protein level comparing to the DOX only proper group, it may be concluded that the oxidative stress is not related to the expression of the enzyme.

Similarly, iNOS was not responsible for the increased oxidative protein level because these elevations in group $\mathrm{DOX}+\mathrm{MET}_{\mathrm{H}}$ were not accompanied by an increase of the enzyme concentration. Moreover, for the lowest and middle doses of doxorubicin, the immunoexpression of iNOS was lower in group DOX $+\mathrm{MET}_{\mathrm{H}}$ comparing to euthyroid rats (proper group of DOX only).

Generally, there were no effects of iodothyronine hormone status on the activity of xanthine oxidase in rats receiving doxorubicin. Furthermore, this enzyme cannot be responsible for the observed oxidative protein elevation in all groups of DOX $+\mathrm{MET}_{\mathrm{H}}$.

Collectively, hypothyroid-like state may intensify the oxidative stress caused by doxorubicin, but P450R, iNOS, and $\mathrm{XO}$ may be excluded as being responsible for these phenomena. Further studies are needed to explain the role of other doxorubicin biactivating enzymes, especially of the mitochondrial fraction.

\section{Acknowledgment}

The authors would like to thank Ms. Mariola Michalczuk for technical support.

\section{References}

[1] G. Minotti, P. Menna, E. Salvatorelli, G. Cairo, and L. Gianni, "Anthracyclines: molecular advances and pharmacologie developments in antitumor activity and cardiotoxicity," Pharmacological Reviews, vol. 56, no. 2, pp. 185-229, 2004.

[2] A. L. A. Ferreira, L. S. Matsubara, and B. B. Matsubara, "Anthracycline-induced cardiotoxicity," Cardiovascular and Hematological Agents in Medicinal Chemistry, vol. 6, no. 4, pp. 278-281, 2008.

[3] A. E. Ashour, M. M. Sayed-Ahmed, A. R. Abd-Allah et al., "Metformin rescues the myocardium from doxorubicininduced energy starvation and mitochondrial damage in rats," Oxidative Medicine and Cellular Longevity, vol. 2012, Article ID 434195, 13 pages, 2012.

[4] J. Dudka, F. Burdan, A. Korga et al., "The diagnosis of anthracycline-induced cardiac damage and heart failure," Postępy Higieny i Medycyny Doświadczalnej, vol. 63, pp. 225-233, 2009.

[5] Y. W. Zhang, J. Shi, Y. J. Li, and L. Wei, "Cardiomyocyte death in doxorubicin-induced cardiotoxicity," Archivum Immunologiae et Therapiae Experimentalis, vol. 57, pp. 435-445, 2009.

[6] V. A. Sardão, P. J. Oliveira, J. Holy, C. R. Oliveira, and K. B. Wallace, "Morphological alterations induced by doxorubicin on H9c2 myoblasts: nuclear, mitochondrial, and cytoskeletal targets," Cell Biology and Toxicology, vol. 25, no. 3, pp. 227243, 2009.

[7] J. M. Berthiaume and K. B. Wallace, "Persistent alterations to the gene expression profile of the heart subsequent to chronic doxorubicin treatment," Cardiovascular Toxicology, vol. 7, no. 3, pp. 178-191, 2007.

[8] M. Tokarska-Schlattner, T. Wallimann, and U. Schlattner, "Alterations in myocardial energy metabolism induced by the anti-cancer drug doxorubicin," Comptes Rendus Biologies, vol. 329, no. 9, pp. 657-668, 2006.

[9] J. Dudka, "The role of reactive oxygen and nitrogen species in calcium and iron homeostasis dysregulation in anthracycline cardiotoxicity," Postępy Higieny i Medycyny Doświadczalnej, vol. 60, pp. 241-247, 2006.

[10] M. J. Mihm, F. Yu, D. M. Weinstein, P. J. Reiser, and J. A. Bauer, "Intracellular distribution of peroxynitrite during doxorubicin 
cardiomyopathy: Evidence for selective impairment of myofibrillar creatine kinase," British Journal of Pharmacology, vol. 135, no. 3, pp. 581-588, 2002.

[11] N. B. Surmeli, N. K. Litterman, A. F. Miller, and J. T. Groves, "Peroxynitrite mediates active site tyrosine nitration in manganese superoxide dismutase. evidence of a role for the carbonate radical anion," Journal of the American Chemical Society, vol. 132, no. 48, pp. 17174-17185, 2010.

[12] S. Deng, A. Kruger, A. L. Kleschyov, L. Kalinowski, A. Daiber, and L. Wojnowski, "Gp91phox-containing NAD(P)H oxidase increases superoxide formation by doxorubicin and NADPH," Free Radical Biology and Medicine, vol. 42, no. 4, pp. 466-473, 2007.

[13] N. R. Bachur, S. L. Gordon, and M. V. Gee, "A general mechanism for microsomal activation of quinone anticancer agents to free radicals," Cancer Research, vol. 38, no. 6, pp. 1745-1750, 1978.

[14] S. Fogli, P. Nieri, and M. C. Breschi, "The role of nitric oxide in anthracycline toxicity and prospects for pharmacologic prevention of cardiac damage," FASEB Journal, vol. 18, no. 6, pp. 664-675, 2004.

[15] P. Mukhopadhyay, M. Rajesh, S. Bátkai et al., "Role of superoxide, nitric oxide, and peroxynitrite in doxorubicin-induced cell death in vivo and in vitro," American Journal of Physiology, vol. 296, no. 5, pp. H1466-H1483, 2009.

[16] D. L. Gustafson, J. D. Swanson, and C. A. Pritsos, "Role fo xanthine oxidase in the potentiation of doxorubicin-induced cardiotoxicity by mitomycin C," Cancer Communications, vol. 3, no. 9, pp. 299-304, 1991.

[17] K. J. A. Davies and J. H. Doroshow, "Redox cycling of anthracyclines by cardiac mitochondria. I. Anthracycline radical formation by NADH dehydrogenase," Journal of Biological Chemistry, vol. 261, no. 7, pp. 3060-3067, 1986.

[18] M. K. Tee, N. Huang, I. Damm, and W. L. Miller, "Transcriptional regulation of the human $\mathrm{p} 450$ oxidoreductase gene: Hormonal regulation and influence of promoter polymorphisms," Molecular Endocrinology, vol. 25, no. 5, pp. 715-731, 2011.

[19] H. C. Li, D. Liu, and D. J. Waxman, “Transcriptional induction of hepatic NADPH: cytochrome P450 oxidoreductase by thyroid hormone," Molecular Pharmacology, vol. 59, no. 5, pp. 987-995, 2001.

[20] P. A. Ram and D. J. Waxman, "Thyroid hormone stimulation of NADPH P450 reductase expression in liver and extrahepatic tissues. Regulation by multiple mechanisms," Journal of Biological Chemistry, vol. 267, no. 5, pp. 3294-3301, 1992.

[21] A. Virdis, R. Colucci, M. Fornai et al., "Inducible nitric oxide synthase is involved in endothelial dysfunction of mesenteric small arteries from hypothyroid rats," Endocrinology, vol. 150, no. 2, pp. 1033-1042, 2009.

[22] H. U. Bergmeyer, K. Gawehn, and M. W. Grassel, Methods of Enzymatic Analysis, vol. 1, Edited by H. U. Bergmeyer, Academic Press, New York, NY, USA, 1974.

[23] A. P. Garner, M. J. I. Paine, I. Rodriguez-Crespo et al., "Nitric oxide synthases catalyze the activation of redox cycling and bioreductive anticancer agents," Cancer Research, vol. 59, no. 8, pp. 1929-1934, 1999.

[24] J. Vásquez-Vivar, P. Martasek, N. Hogg, B. S. S. Masters, K. A. Pritchard Jr., and B. Kalyanaraman, "Endothelial nitric oxide synthase-dependent superoxide generation from adriamycin," Biochemistry, vol. 36, no. 38, pp. 11293-11297, 1997.

[25] S. Chattopadhyay, G. Zaidi, K. Das, and G. B. N. Chainy, "Effects of hypothyroidism induced by 6-n-propylthiouracil and its reversal by $\mathrm{T} 3$ on rat heart superoxide dismutase, catalase and lipid peroxidation," Indian Journal of Experimental Biology, vol. 41, no. 8, pp. 846-849, 2003.

[26] M. Jain, D. A. Brenner, L. Cui et al., "Glucose-6-phosphate dehydrogenase modulates cytosolic redox status and contractile phenotype in adult cardiomyocytes," Circulation Research, vol. 93, no. 2, pp. e9-16, 2003.

[27] A. Lombardi, L. Beneduce, M. Moreno et al., "3,5-Diiodo-Lthyronine regulates glucose-6-phosphate dehydrogenase activity in the rat," Endocrinology, vol. 141, no. 5, pp. 1729-1734, 2000.

[28] C. M. Palmeira, J. Serrano, D. W. Kuehl, and K. B. Wallace, "Preferential oxidation of cardiac mitochondrial DNA following acute intoxication with doxorubicin," Biochimica et Biophysica Acta, vol. 1321, no. 2, pp. 101-106, 1997.

[29] E. Fadillioglu, E. Oztas, H. Erdogan et al., "Protective effects of caffeic acid phenethyl ester on doxorubicin-induced cardiotoxicity in rats," Journal of Applied Toxicology, vol. 24, no. 1, pp. 47-52, 2004.

[30] M. A. Mansour, A. G. El-Din, M. N. Nagi, O. A. Al-Shabanah, and A. M. Al-Bekairi, "N $\omega$-Nitro-L-Arginine Methylester Ameliorates Myocardial Toxicity Induced by Doxorubicin," Journal of Biochemistry and Molecular Biology, vol. 36, no. 6, pp. 593-596, 2003.

[31] Z. Bolaman, C. Cicek, G. Kadikoylu et al., "The protective effects of amifostine on adriamycin-induced acute cardiotoxicity in rats," Tohoku Journal of Experimental Medicine, vol. 207, no. 4, pp. 249-253, 2005.

[32] X. Sun and Y. J. Kang, "Prior increase in metallothionein levels is required to prevent doxorubicin cardiotoxicity," Experimental Biology and Medicine, vol. 227, no. 8, pp. 652657, 2002.

[33] T. Li, I. Danelisen, and P. K. Singal, "Early changes in myocardial antioxidant enzymes in rats treated with adriamycin," Molecular and Cellular Biochemistry, vol. 232, no. 1-2, pp. 1926, 2002.

[34] T. Grune, T. Reinheckel, and K. J. A. Davies, "Degradation of oxidized proteins in K562 human hematopoietic cells by proteasome," Journal of Biological Chemistry, vol. 271, no. 26, pp. 15504-15509, 1996.

[35] T. Grune, T. Reinheckel, M. Joshi, and K. J. A. Davies, "Proteolysis in cultured liver epithelial cells during oxidative stress. Role of the multicatalytic proteinase complex, proteasome," Journal of Biological Chemistry, vol. 270, no. 5, pp. 2344-2351, 1995.

[36] W. G. Siems, H. Zollner, T. Grune, and H. Esterbauer, "Metabolic fate of 4-hydroxynonenal in hepatocytes: 1,4dihydroxynonene is not the main product," Journal of Lipid Research, vol. 38, no. 3, pp. 612-622, 1997.

[37] W. M. Przybyszewski, J. Kasperczyk, K. Stoklosa, and A. Bkhiyan, "DNA damage induced by products of lipid peroxidation," Postępy Higieny i Medycyny Doświadczalnej, vol. 59, pp. 75-81, 2005.

[38] L. J. Marnett, J. N. Riggins, and J. D. West, "Endogenous generation of reactive oxidants and electrophiles and their reactions with DNA and protein," Journal of Clinical Investigation, vol. 111, no. 5, pp. 583-593, 2003.

[39] L. J. Marnett, "Lipid peroxidation - DNA damage by malondialdehyde," Mutation Research, vol. 424, no. 1-2, pp. 83-95, 1999.

[40] P. Møller and H. Wallin, "Adduct formation, mutagenesis and nucleotide excision repair of DNA damage produced by reactive oxygen species and lipid peroxidation product," Mutation Research, vol. 410, no. 3, pp. 271-290, 1998. 
[41] I. Dalle-Donne, R. Rossi, D. Giustarini, A. Milzani, and R. Colombo, "Protein carbonyl groups as biomarkers of oxidative stress," Clinica Chimica Acta, vol. 329, no. 1-2, pp. 23-38, 2003.

[42] A. Flores-Morales, H. Gullberg, L. Fernandez et al., "Patterns of liver gene expression governed by TR $\beta$," Molecular Endocrinology, vol. 16, no. 6, pp. 1257-1268, 2002. 


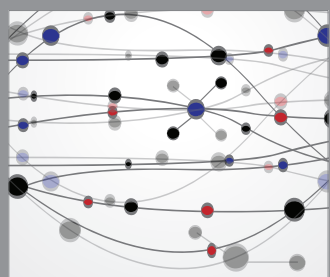

The Scientific World Journal




Gastroenterology

Research and Practice
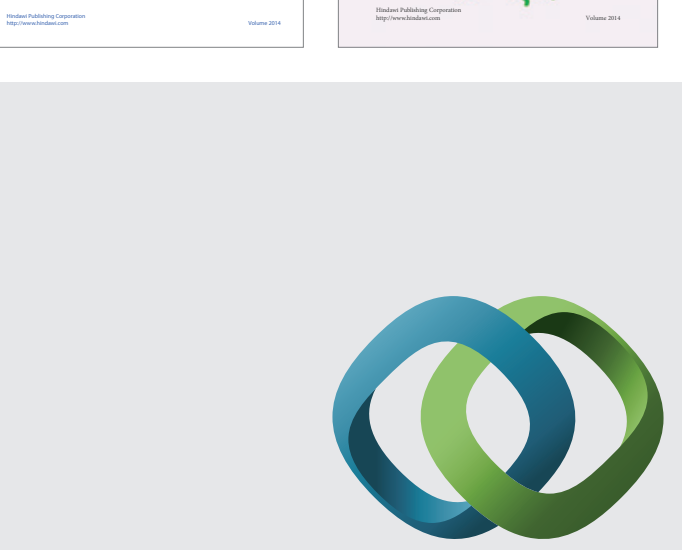

\section{Hindawi}

Submit your manuscripts at

http://www.hindawi.com


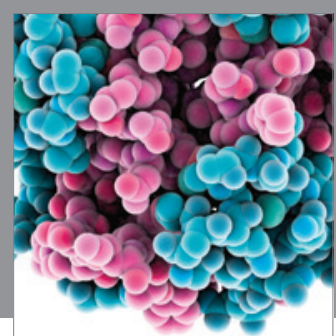

Journal of
Diabetes Research

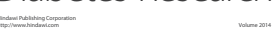

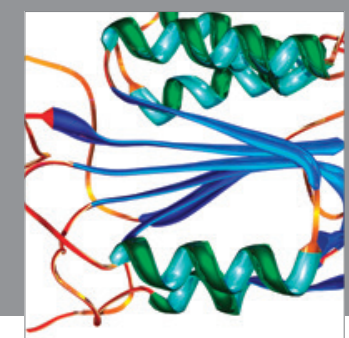

Disease Markers
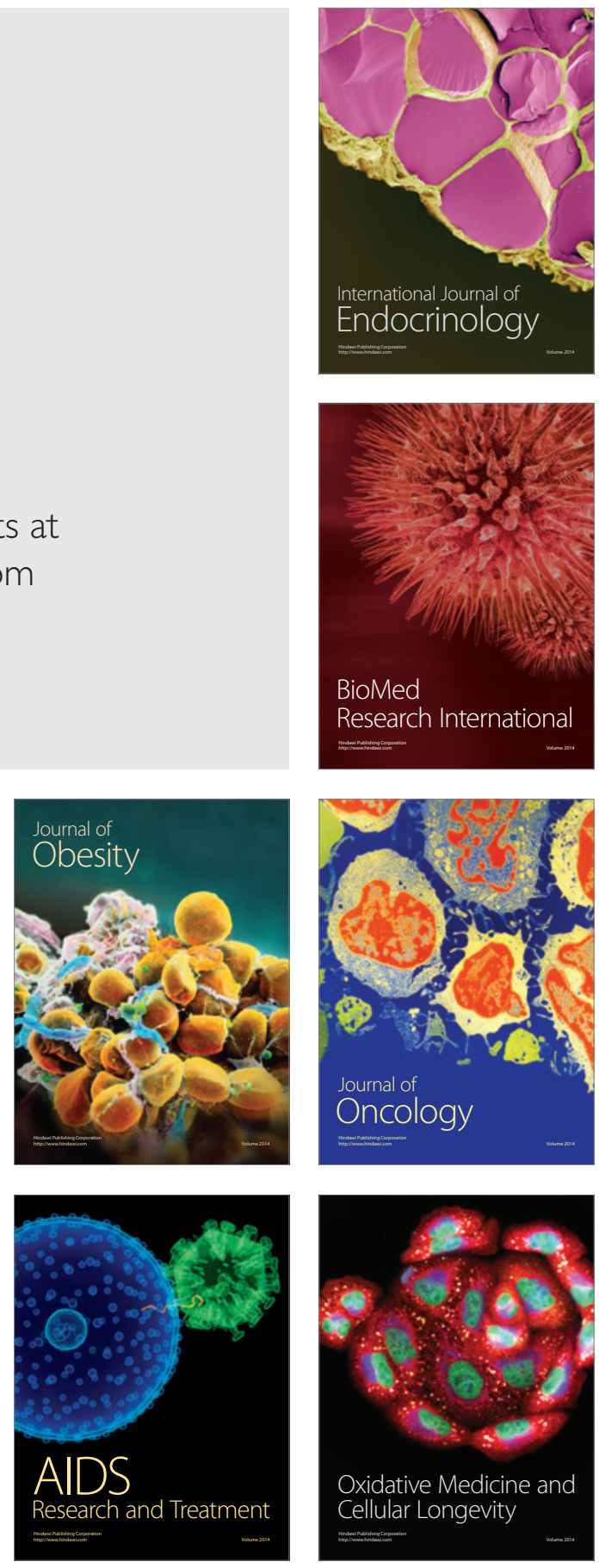